\title{
Solitary Hair Cells Are Distributed Throughout the Extramacular Epithelium in the Bullfrog's Saccule
}

\author{
Jonathan E. Gale, Jason R. Meyers, and Jeffrey T. Corwin \\ Department of Otolaryngology-H NS and Department of Neuroscience, University of Virginia School of M edicine, \\ Charlottesville, VA 22908, USA
}

Received: 27 March 2000; Accepted: 5 June 2000; O nline publication: 29 August 2000

\section{ABSTRACT}

The frog inner ear contains eight sensory organs that provide sensitivities to auditory, vestibular, and ground-borne vibrational stimuli. The saccule in bullfrogs is responsible for detecting ground- and airborne vibrations and is used for studies of hair cell physiology, development, and regeneration. Based on hair bundle morphology, a number of hair cell types have been defined in this organ. Using immunocytochemistry, vital labeling, and electron microscopy, we have characterized a new hair cell type in the bullfrog saccule. A monoclonal antibody that is specific to hair cells revealed that a population of solitary hair cells exists outside the sensory macula in what was previously thought to be nonsensory epithelium. We call these extramacular hair cells. There are 80-100 extramacular hair cells in both tadpole and adult saccules, which extend up to $1 \mathrm{~mm}$ from the edge of the sensory macula. The extramacular hair cells have spherical cell bodies and small apical surfaces. Even in adults, the hair bundles of the extramacular cells appear immature, with a long kinocilium (6-9 $\mu \mathrm{m})$ and short stereocilia $(0.5-2 \mu \mathrm{m})$. At least $90 \%$ of extramacular hair cells are likely to be innervated as demonstrated by labeling of nerve fibers with an antineurofilament antibody. The extramacular hair cells may differentiate in regions just beyond the edge of the macula at an early stage in development and then be pushed out via the interstitial growth of the epithelium that surrounds the macula. It is also possible that they may be produced from cell divisions in the extramacular epithe-

Correspondence to: Jonathan E. Gale - Department of Physiology • University College London - Gower Street - London WC1E 6BT, UK. Telephone: 44-207-67-6546; fax: 44-207-387-6368; email: j.e.gale@ucl.ac.uk lium that has not been considered capable of giving rise to hair cells.

Keywords: hair cell, vestibular, balance, bullfrog, amphibian, sacculus, vital dye

\section{INTRO DUCTION}

The saccule of the bullfrog, Rana catesbieana, is sensitive to substrate and air-borne vibrations ( Lewis et al. 1985). The saccular macula has been used for the study of hair cell anatomy and development ( $\mathrm{Hillman}$ and Lewis 1971; Lewis and Li 1973, 1975; Kelley et al. 1992), hair cell physiology (Hudspeth and Corey 1977; Corey and Hudspeth 1979; Hudspeth 1989), and more recently hair cell regeneration (Baird et al. 1993; Steyger et al. 1997; Gale and Corwin 1997).

The amphibian sacculus increases in size throughout life via the addition of hair cells, the majority of which are added in a growth zone around the outer edge of the macula (Corwin 1985). Heterogeneity in the hair bundlesismost notable at the peripheral edge of the saccular macula, as it is in other species that produce and accumulate hair cells during postembryonic life (Lewisand Li 1973, 1975; Cor win 1981; Kelley et al. 1992). At one extreme the bundles have short, thin stereocilia and a tall kinocilium that is significantly longer than the tallest stereocilia. At the other extreme the cells have longer, thicker stereocilia and a kinocilium that isapproximatelythe same height as the tallest stereocilia, which is the bundle morphology typical for the mature cells in the center of the macula. In the bullfrog utricule, another vestibular organ, distinct physiological properties have been measured in cells with different hair bundle types (Lewis et al. 1982; Baird and Lewis 1986; Baird 1994a,b). 
A hindrance to hair cell research has been the lack of markers for hair cells. In an effort to address that problem, we have developed lines of hybridomas that secrete monoclonal antibodies against components of hair cell epithelia. One of those monoclonal antibodies binds to a protein in the cell bodies of hair cells in fish, amphibians, birds, and mammals (Finley et al. 1997). After immunocytochemical labeling with that antibody, we noticed numerous solitary cells labeled in the nonsensor y epithelium surrounding the bullfrog's saccular macula. H ere we report an immunocytochemical, vital labeling, and electron microscopic characterization of solitary hair cells that are distributed between the edge of the sensory macula and the extreme outer edge of the nonsensory epithelium. The presence of small hair bundles outside the macula proper has been noted (Lewis and Li 1973) and those cells may be a subset of the population we have investigated. This work has been presented in a preliminary form (Gale and Corwin 1998).

\section{MATERIALS AND METHODS}

Adult bullfrogs and tadpole larvae ( $R$ ana catesbeiana) were anesthetized in crushed ice and then pithed. Tadpoles were staged according to Gosner (1960). The saccules were dissected in a low-calcium, HEPES-buffered frog Ringer's, and placed in $50 \mu \mathrm{g} / \mathrm{ml}$ subtilisin (Sigma, City, State USA) for $15 \mathrm{~min}$. The otolithic membrane was then removed using agentle flow of solution.

Saccules prepared for immunocytochemistry were fixed with $4 \%$ paraformaldehyde in $0.1 \mathrm{M}$ sodium cacodylate, $\mathrm{pH}$ 7.4. Then they were immunolabeled using a 1:100 dilution of the monoclonal antibody HCS-1, which specifically labels the cell bodies of hair cells (Finley et al. 1997). A 1:100 dilution of a polyclonal rabbit anti-neurofilament 145 antibody (Chemicon, city, state USA) was used to label nerve fibers in the saccular epithelium. Specimens were incubated in primary antibodies in $0.1 \mathrm{M}$ PBS with $5 \%$ NGS and $0.1 \%$ Triton X-100 (blocking solution) overnight at $4^{\circ} \mathrm{C}$. Subsequently, saccules were incubated for $1 \mathrm{~h}$ at room temperature in a 1:200 dilution of a Cy3-conjugated goat antimouse lgG secondary antibody followed by a Ih incubation at room temperature in a 1:100 dilution of a FITC-conjugated swine antirabbit IgG secondary antibody (Jackson Laboratories, Bar Harbor, ME, USA). FITC-conjugated phalloidin was used at $0.5 \mu \mathrm{g} /$ $\mathrm{ml}$ for $1 \mathrm{~h}$ at room temperature to stain filamentous actin.

FM 1-43 (Molecular Probes, City, State USA) is a styryl dye that does not cross the lipid bilayer and is used as a tool for studying exo- and endocytosis at the neuromuscular junction (Betz et al. 1992). Live saccules were incubated in $30 \mu \mathrm{M}$ FM 1-43 for 5 min at room temperature, washed in HEPES-buffered saline, and imaged on a Zeiss LSM confocal microscope.

For scanning electron microscopy (SEM), saccules were prefixed with $1 \% \mathrm{OsO}_{4}$ for $10 \mathrm{~min}$, then fixed in $2 \%$ glutaraldehyde and $2 \%$ paraformaldehyde in $0.1 \mathrm{M}$ sodium cacodylate at $\mathrm{pH} 7.4$ for $1 \mathrm{~h}$. SEM samples were prepared by standard methods (Corwin 1985), except that they were made electrically conductive by binding of osmium achieved via infiltration with thiocarbohydrazide before critical point drying (Malick and Wilson 1974). Dried samples were examined in a JEOL 6400 scanning electron microscope. Images were recorded digitally and photographed with Polaroid film.

Thirty cartilagenous capsules containing the inner ear were dissected from 15 tadpoles. The capsules were opened up in order to allow culture medium access to the inner ear. Then they were cultured in Wolf and Quimby medium (Gibco, City, State, USA) with added sodium pyruvate, nonessential MEM amino acids, and ciprofloxacin, according to the method of Baird et al. (1993; personal communication). 5-Bromo-2-deoxyuridine ( $\mathrm{BrdU}, 3 \mu \mathrm{g} / \mathrm{ml}$ ) wasadded to the medium from the start of each culture. After 7 or 14 days in vitro, all the capsules were fixed with paraformaldehyde as described above. The saccules were dissected out from the cartilagenous capsules and treated with $2 \mathrm{~N} \mathrm{HCl}$ for $45 \mathrm{~min}$ at room temperature to denature DNA. Then the specimens were double-labeled with a mouse anti-BrdU antibody (1:60; Dickinson, Becton city, CA) and a goat anti-calretinin polyclonal antibody ( 1:100; Swant, Bellinzona, Switzerland). Specimens were analyzed on a Zeiss Axioplan fluorescence microscope interfaced with a cooled CCD camera (Princeton Instruments, Princeton, NJ, USA) that was controlled by Metamorph software (Universal Imaging Inc., Media, PA). The data and images shown are all from adult frogs unless indicated. All values shown are means \pm s.d.

\section{RESU LTS}

\section{Antibody Labeling and SEM O bservations of} Hair Cells $O$ utside the Saccular Macula

SEM shows the kidney-shaped macula of the bullfrog saccule (Fig. 1A). In an adult bullfrog the macula is approximately $500 \mu \mathrm{m}$ across and contains approximately 2500 hair cells (Lewis and Li 1973). Immunolabeling with the monoclonal antibody HCS-1 reveals the cell bodies of hair cells in the saccular macula (Fig. 1B). Double labeling with fluorescent phalloidin stains filamentous actin in the stereocilia atop the cell bodies 

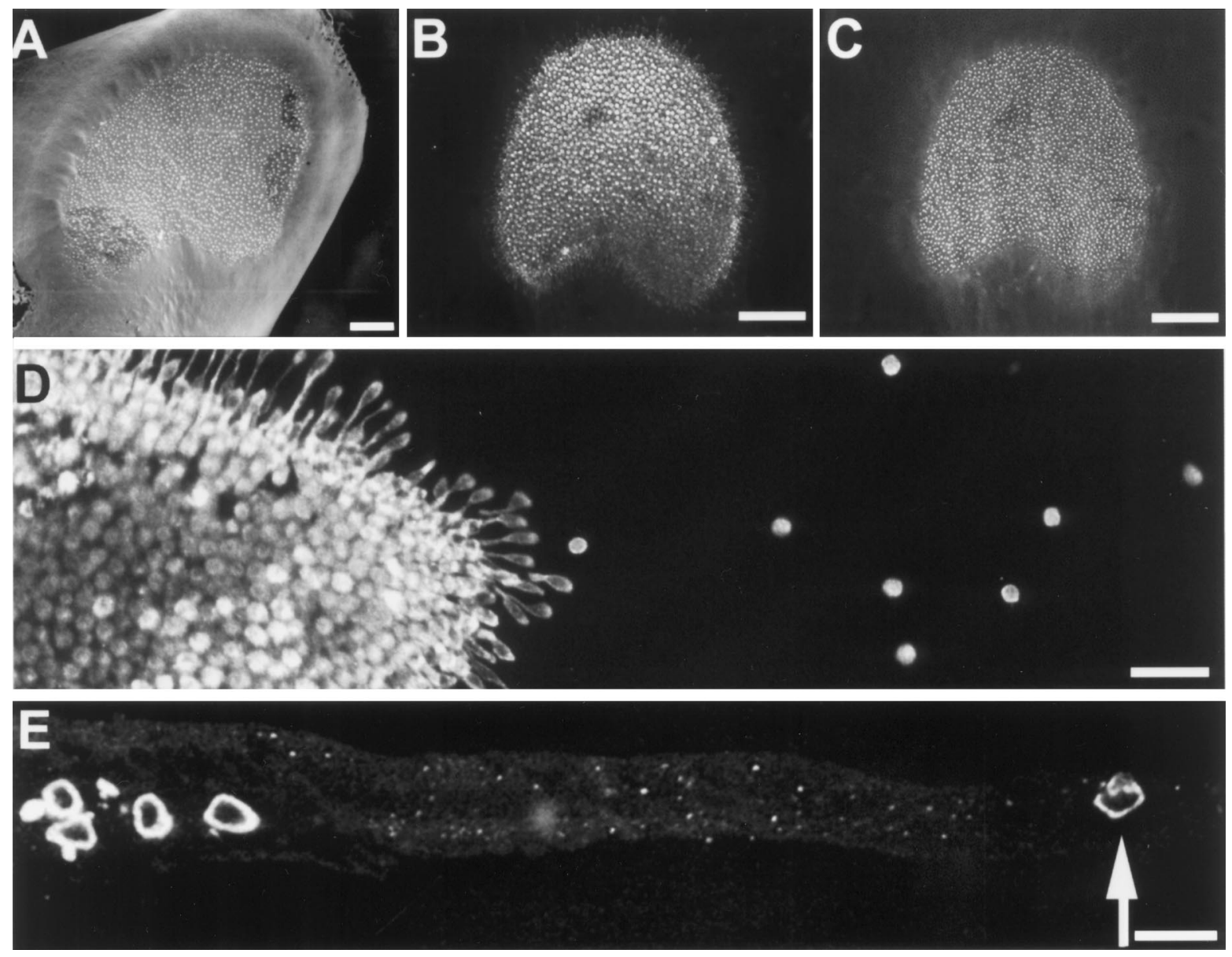

FIG. 1. Micrographs of extramacular hair cells in the bullfrog saccule. A. A low-magnification SEM photomicrograph of a bullfrog saccule showing hair bundles projecting from the surface of the kidney-shaped macula. B. Immunofluorescent labeling of a different saccule with monoclonal antibody HCS-1 (see M ethods) reveals hair cells in the sensory macula region. $\mathbf{C}$. Double-labeling of the same saccule in B with FITC-conjugated phalloidin reveals hair bundles associated with the HCS-1-labeled hair cell bodies. At higher magnifi-

stained by HCS-1 (Fig. 1C). Examination of the HCS1-labeled saccular preparations revealed cells in the nonsensory epithelium that were far outside of the macula (Fig. 1D,E).

\section{Morphological characteristics of the extramacular hair cells}

The cells in the nonsensory epithelium that were labeled by the HCS-1 antibody (Fig. 2A) were confirmed as hair cells by the presence of small actin-rich hair bundles at their apical surfaces that stain with phalloidin (Fig. 2B). We have termed the cells extramacular hair cells, because they are distributed throughout the epithelium that extends outside the macula. Extramacular hair cells have an atypical morphology. They have rotund cell bodies with a mean diameter of 12 $\pm 1 \mu \mathrm{m}(\mathrm{n}=22$, Fig. $2 \mathrm{~A})$. This shape is qualitatively cation, HCS-1 labeling reveals numerous solitary hair cells in the nonsensory or extramacular epithelium. $\mathbf{E}$. Cryostat cross section of a bullfrog saccule that was labeled with HCS-1 reveals an extramacular hair cell (arrow) that is $200 \mu \mathrm{m}$ from the edge of the macula. Four hair cells at the edge of the macula are visible near the left edge of the photo. (A-C) scale bar $=200 \mu \mathrm{m}$, (D) scale bar $=50 \mu \mathrm{m},(E)$ scale bar $=25 \mu \mathrm{m}$.

different from the cylindrical and flasklike cell bodies of the hair cells within the saccular macula (Wersall and Bagger-Sjoback 1974). The apical surface of the cells is narrow, $3.0 \pm 0.6 \mu \mathrm{m}$ in diameter $(n=6)$, compared with hair cells in the macula (Figs. 1E,2B). The hair bundles atop the extramacular hair cells are similar to the type A hair bundles at the peripheral edge of the macula that are thought to be immature (Lewis and Li 1975; Corwin 1981, 1985; Kelley et al. 1992). They are composed of short (0.6-2.2 $\mu \mathrm{m})$ and narrow ( $171 \pm 20 \mathrm{~nm}$ ) stereocilia ( $\mathrm{n}=37$ from 6 hair bundles) that form small hair bundles with a long kinocilium ( $7.3 \pm 1.1 \mu \mathrm{m}$, range 6-9 $\mu \mathrm{m}, \mathrm{n}=6$ ) that is typically four to nine times the size of the stereocilia in the same cell's bundle (Fig. 2D).

Extramacular hair cells were also labeled in living saccules using the styryl dye FM 1-43. FM 1-43 labels the cytoplasm of both the extramacular cells and all of the 

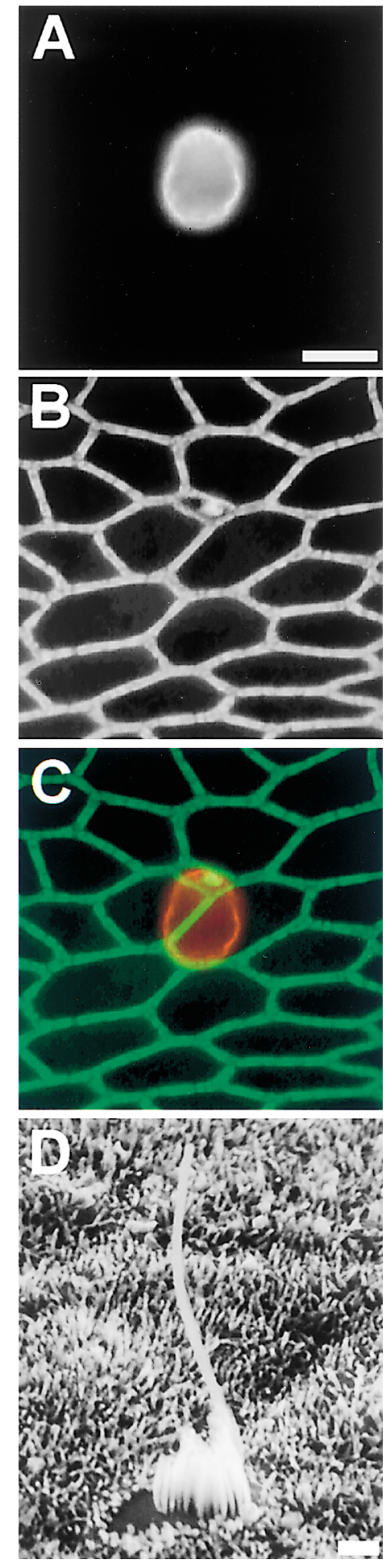

FIG. 2. Extramacular hair cells have small hair bundles. Labeling of a single extramacular hair cell body with HCS-1 (A) and labelling of its hair bundle with FITC-conjugated phalloidin (B) have been imaged in two different focal planes to show the hair bundle and the cell body that is beneath the surface of the epithelium The two images are superimposed in $\mathbf{C}$ to show the small hair bundle and small apical surface of the extramacular hair cell. HCS-1 is red and FITC-phalloidin labeled actin is green. D. SEM view of the hair bundle of another extramacular hair cell. The hair bundle of the cell has the tall kinocilium and short stereocilia that are characteristic for extramacular hair cells. (A-C) scale bar $=10 \mu \mathrm{m}$, (D) scale bar $=1 \mu \mathrm{m}$. hair cells in the saccular macula (Fig. 3A,F). Bundles were visible above each of the FM 1-43-labeled extramacular hair cells (Fig. 3B-E) . XZ confocal reconstructions of optical sections reveal the same rotund cell bodies of the extramacular hair cells in living preparations as were observed by immunohistochemistry in fixed specimens (Fig. 3G,H).

\section{Innervation of extramacular hair cells}

In order to test whether these cellsmight communicate with the central nervous system (CNS), we doublelabeled saccules with an anti-neurofilament antibody (see M ethods) and the HCS-1 antibody. The anti-neurofilament antibody labeled nerve fibersthat projected out from the macula and extended to each of the extramacular hair cells (Fig. 4A). Of 97 extramacular cells in four adult saccules, 87 (89.7\%) were found to have nerve fibers coming into intimate proximity with the cell bodies (Fig. 4B). This may well be an underestimate because very fine neuronal fibers were often difficult to distinguish against the background fluorescence. In many cases a ner ve fiber appeared to contact more than one extramacular hair cell. The extramacular fibers often coursed in fascicles with other fibers. Identical double-labeling procedures applied to tadpole saccules revealed that extramacular hair cells were present and nerve fibers were once again observed in close proximity suggesting that the cells are innervated in the larval ear (Fig. 4C).

\section{Distribution of extramacular hair cells throughout the epithelium}

As visualized in both SEM and immunocytochemical preparations, extramacular hair cells were distributed throughout most of the nonsensory epithelium. Extramacular hair cells were observed at distances up to 1 $\mathrm{mm}$ from the edge of the macula. Extramacular hair cells were also observed out at the extreme edge of the surrounding columnar epithelium (Figs. 4D, 5A,B), where there is an abrupt transition to a squamous epithelium. The transition is marked by much lower levels of filamentous actin in the circumferential bands that course near the intercellular junctions (Fig. 4D).

To determine the distribution of extramacular hair cells, six saccules from three adult bullfrogs of similar body length $(12 \mathrm{~cm})$ were labeled with HCS-1 and studied in detail. A total of 489 extramacular hair cells were analyzed. Figure 5C,D shows representative plots of the position of the extramacular hair cells in saccules from the right and left ears.

There was one noticeable feature of the general distribution of extramacular hair cells: They were distributed relatively uniformly around three-quarters of 

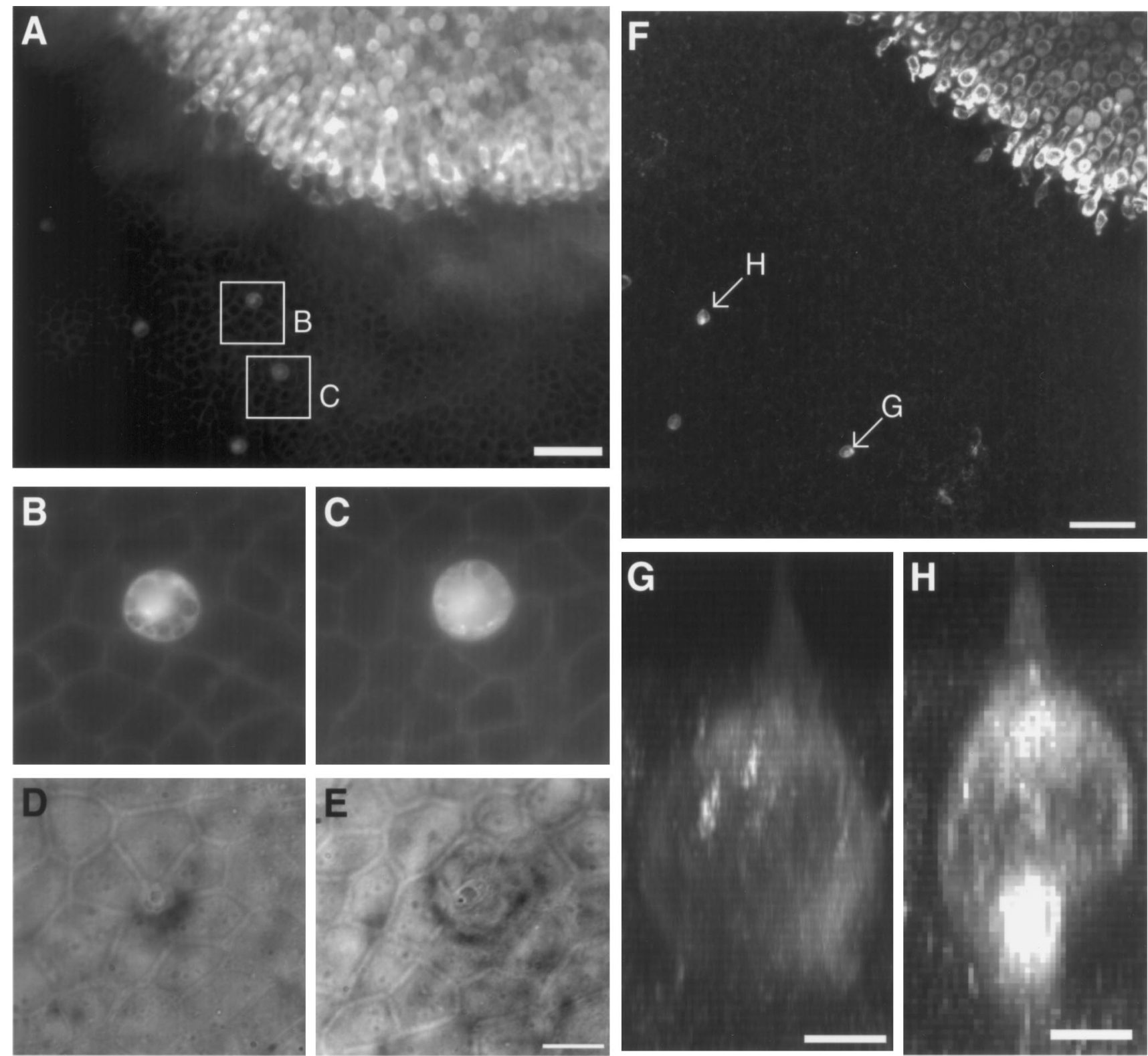

FIG. 3. Extramacular hair cells visualized in living saccules using the styryl dye FM 1-43. A. Fluorescent micrograph of a saccule after loading with FM 1-43 showing the edge of labeled hair cells at the edge of the macula and four extramacular hair cells also labeled with the dye. B, C. Higher-magnification micrographs of the extramacular cells indicated in A. D, E. Light micrographs of the extramacular epithelium showing surface of the extramacular cells in $\mathbf{B}$ and $\mathbf{C}$,

the macula but were only rarely seen in the epithelium directly above the saccular ramus of the VIIIth nerve or in the epithelium anterior to the nerve.

M easurements were made of ( 1 ) the distance of the extramacular hair cells from the edge of the macula and (2) the distance from each extramacular hair cell to its nearest neighboring extramacular hair cell. Data from the six saccules were pooled and frequency histograms were plotted for measurements of the distances from the edge of the macula (Fig. 5E) and from the nearest neighboring hair cell ( Fig. 5F). The mean dis- respectively. A small hair bundle is visible above each labeled cell. F. Projection of a stack of 19 confocal sections (2- $\mu \mathrm{m}$ interval). G, H. XZ econstruction of 50 confocal sections (0.5- $\mu \mathrm{m}$ interval) of the cells indicated in $\mathbf{F}$. unctate intracellular staining is observed along with a more diffuse labeling in the cytoplasm and stereocilia. (A) scale bar $=50 \mu \mathrm{m}$ (B-E) scale bar $=10 \mu \mathrm{m}$, (F) scale bar $=50 \mu \mathrm{m}$, $(\mathrm{G}, \mathrm{H})$ scale bar $=4 \mu \mathrm{m}$.

tance to the nearest neighbor was $87 \pm 47 \mu \mathrm{m}$ ( $\mathrm{n}=$ 489). The data set sampled appears to represent a single population with a distribution that is skewed toward greater distances between the neighboring cells (Fig. 5F). It was noticeable that the hair bundles of the cells at the extreme edge of the columnar extramacular epithelium were indistinguishable from those found closer to the macula. Extramacular cells at the extreme edge and those close to the macula also have the same rotund cell morphology revealed by HCS-1 labeling in whole mounts. 


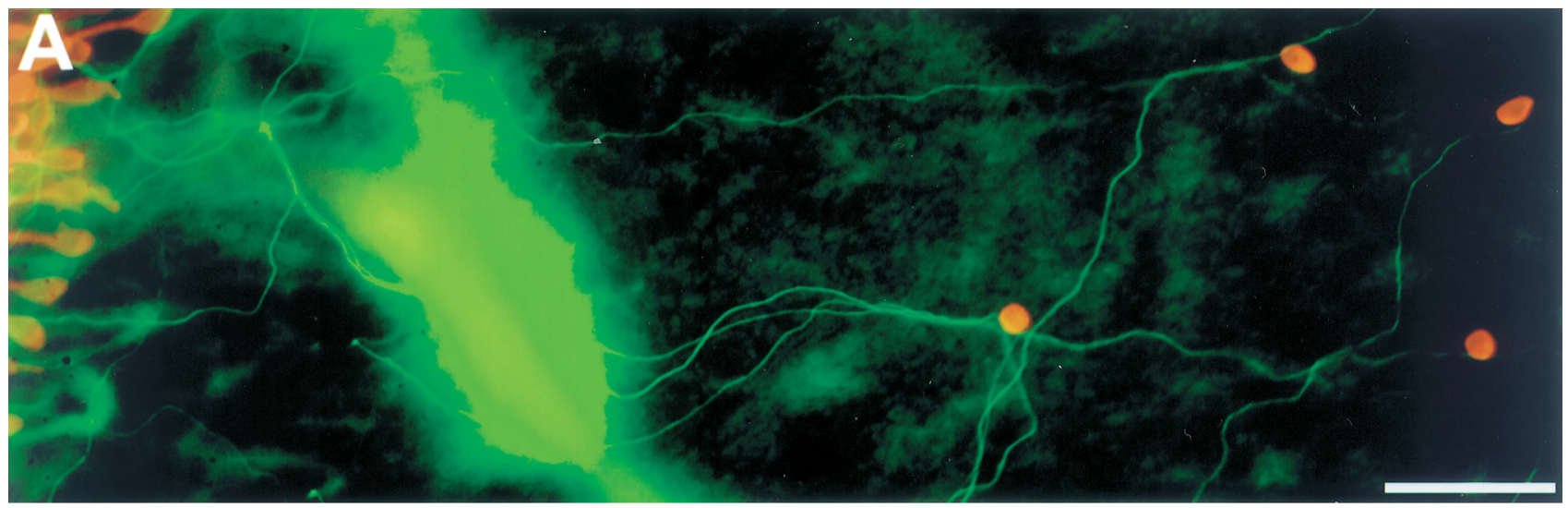

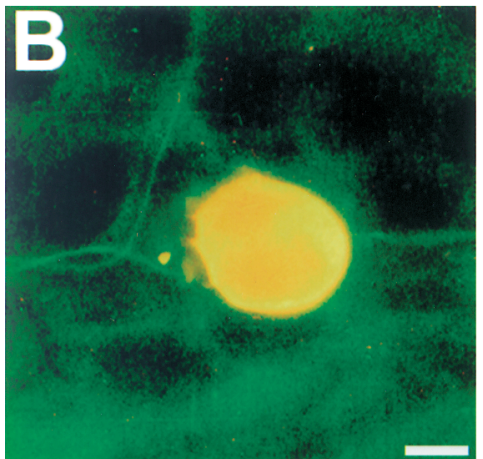
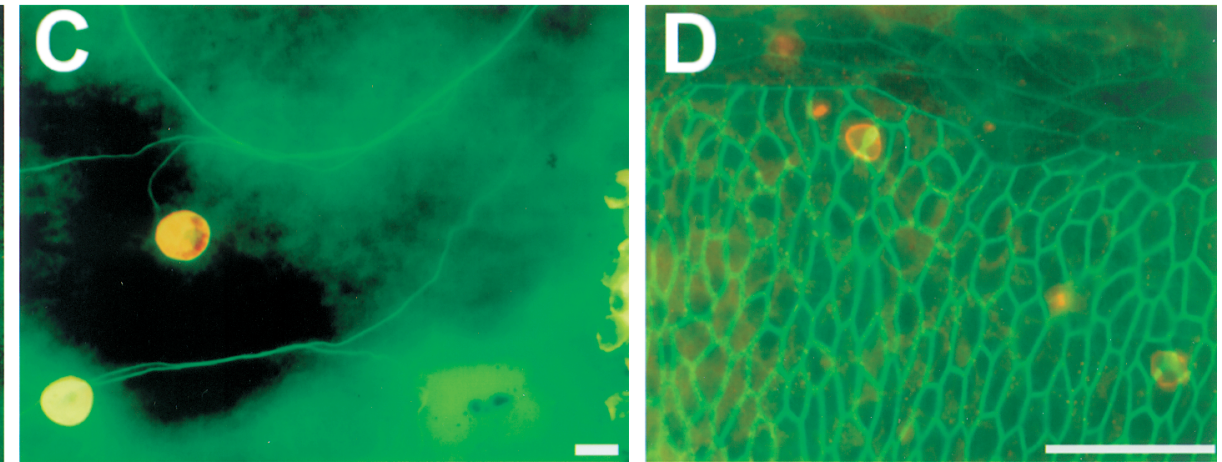

FIG. 4. A. Double-labeling of an adult bullfrog saccule with HCS1 (red) and a polyclonal antineurofilament antibody (green) shows nerve fibers that have grown out from the macula and come into intimate contact with the extramacular hair cells. B. At higher magnification it appears that this fiber contacts the extramacular hair cell. C. Similar double-labeling of the saccule from a stage 39 tadpole shows that extramacular hair cells are already innervated. D. Extramacular cells can be found at distances from the macula proper that are up to two times the diameter of the macula. We have found that there is an abrupt transition in the structure of the epithelium that lines the otic space at about that distance. Labeling with FITC-conjugated phalloidin (green) reveals a reticular network resulting from the intense labeling of circumferential rings of filamentous actin that link

\section{Growth of the saccule and changes in numbers of extramacular hair cells}

We dissected saccules from tadpole larvae at two developmental stages and from two sizes of adult bullfrogs to determine whether developmental changes in the numbers or locations of extramacular hair cells could be observed. As bullfrogs age they increase in size, so the relative age of a frog can be assessed by measuring the nose-to-pelvic girdle length. Figure 6A shows representative saccules from a stage 29 tadpole, that was fixed when the tadpole was just beginning to develop hind limbs (Gosner 1960), and from 12 and 15-cm adult bullfrogs. All were immunolabeled with HCS-1 to stain the hair cells. Figure $6 B, C$ shows measurements of the macula area and of the total number of extramacular hair cells in saccules from stage $29(n=2)$ and stage 39 tadpoles $(n=9)$ and from $12-\mathrm{cm}(n=$ $6)$ and $15-\mathrm{cm}(\mathrm{n}=8)$ adults. The saccular macule the intercellular junctions to the cytoskeletons in the cells of the columnar epithelium that surrounds the macula. At the point of transition to the squamous epithelium that forms the inner lining of the roof of the saccule there is a distinct decrease in the intensity of FITC-phalloidin labeling of the actin rings that course within the intercellular junctions of the squamous cells. The squamous cells are also notably larger in surface area than the cells in the columnar epithelium of the extramacular region. An extramacular hair cell labeled with HCS-1 (red) can be seen at a point that is approximately $10 \mu \mathrm{m}$ from the transition of the columnar extramacular epithelium to the squamous epithelium. (A) scale bar $=75 \mu \mathrm{m}$, (B) scale bar $=$ $5 \mu \mathrm{m}$ (C), scale bar $=10 \mu \mathrm{m}$, (D) scale bar $=50 \mu \mathrm{m}$.

increased in size with the size of the frog, as has been described (Lewis and Li 1973; Corwin 1985). From the earliest stage investigated (Stage 29) to the oldest animals investigated, the mean macular area increased almost fivefold (475\%). Over the period of growth represented by these tadpoles and frogs, the number of extramacular hair cells did not increase. In fact, there was a significant decrease from $101.9 \pm 4.0$ extramacular hair cells in the tadpoles (stage $39, n=9$ ) to $73.5 \pm 6.4$ extramacular cells in the $15-\mathrm{cm}$ adults ( $n=8, p<0.001$, two-tailed t-test).

Are extramacular hair cells produced by cell divisions in the extramacular epithelium?

To test the hypothesis that extramacular cells are produced from the division of cells in the extramacular epithelium, 30 inner ears from stage 29 to stage 39 


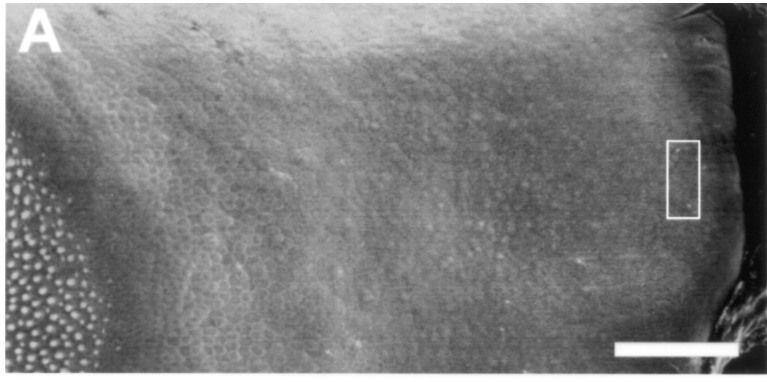

C

LEFT

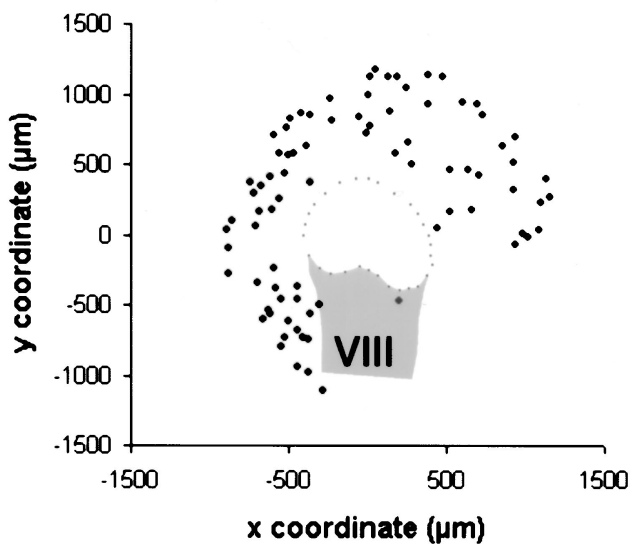

$\mathbf{E}$

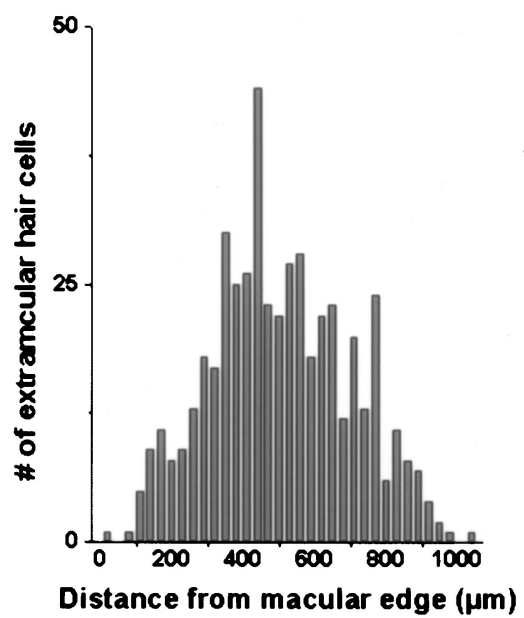

FIG. 5. A. SEM micrograph shows the extramacular epithelium extending up to $600 \mu \mathrm{m}$ from the edge of the macula; the latter is identified by the white hair bundles at the left edge of the panel. $\mathrm{H}$ air cells can be observed close to the edge of the epithelium (boxed, see B). B. The boxed area in A was rotated counterclockwise by $90^{\circ}$ and shown at higher magnification. Two extramacular hair cells that are separated by $3-4$ epithelial cells $(\sim 50 \mu \mathrm{m})$ are visible nearly 600 $\mu \mathrm{m}$ from the edge of the macula. The two hair bundles have essentially the same orientation, which can be determined by the position of the kinocilium. C, D. Graphical plots of the distributions of extramacular hair cells (black diamonds) in two saccules from the right and left ears of $12-\mathrm{cm}$ adult bullfrogs. The edge of the kidney-shaped saccular

tadpoles were dissected and cultured for 1-2 weeks in the presence of BrdU at $3 \mu \mathrm{g} / \mathrm{ml}$. Subsequent doublelabeling of fixed cultures with anti-BrdU and anticalretinin antibodies was used to determine whether any

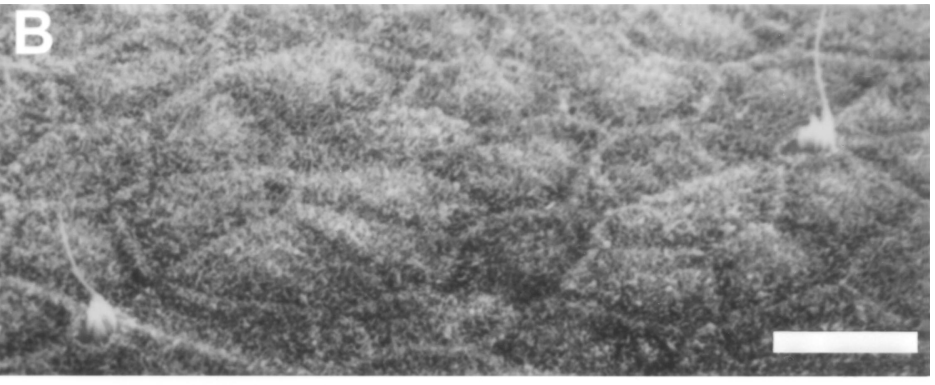

D
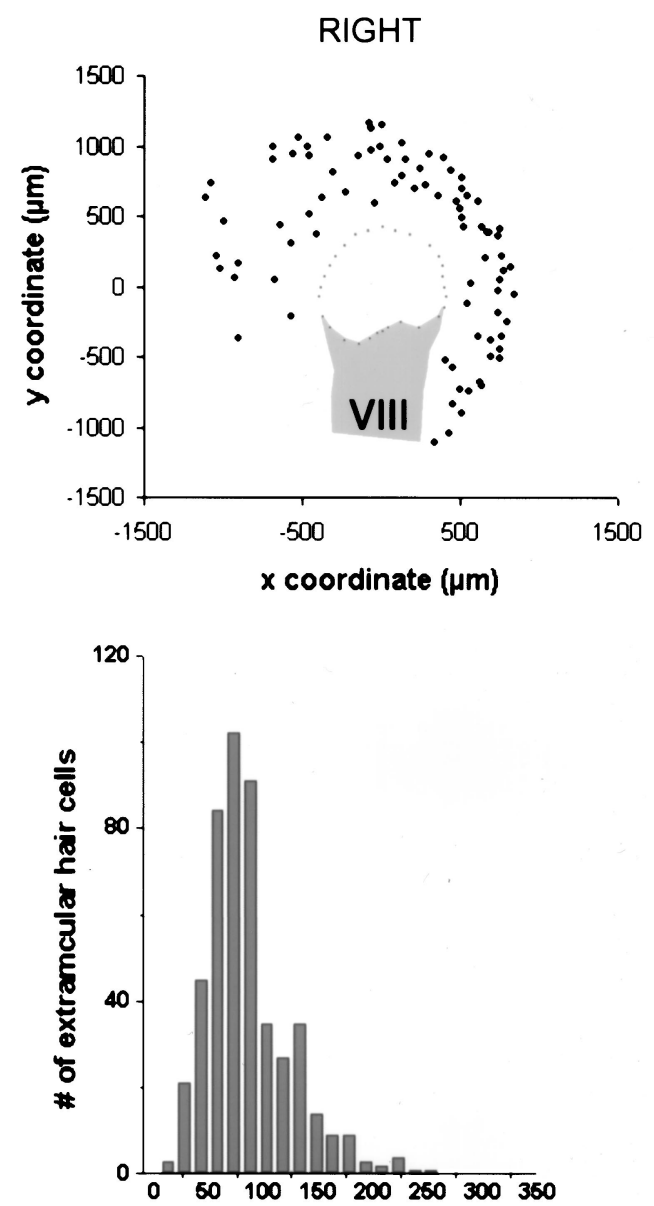

Distance from nearest neighbour $(\boldsymbol{\mu m})$

macula is outlined (small dots), and the approximate course of the saccular branch of the VIIIth nerve is demarcated by the shading (gray). E. Frequency histogram showing the distribution of extramacular cells at increasing distances from the edge of the macula. The distances of 489 extramacular hair cells from the edge of the macula were binned at $30 \mu \mathrm{m}$ intervals. F. Frequency histogram showing the distribution of the distances between nearest-neighboring extramacular hair cells in the same population. The nearest-neighbor distances were binned at $15 \mu \mathrm{m}$ intervals. The mean distance was $87 \mu \mathrm{m}$ with the distribution skewed positively to greater distances. (A) scale bar $=100 \mu \mathrm{m}$, (B) scale bar $=10 \mu \mathrm{m}$.

of the extramacular hair cellshad been produced from cells that divided during the period of culture. Anticalretinin antibodies label a subset of hair cells in the bullfrog saccule that includes the extramacular hair 
A Stage 29 tadpole

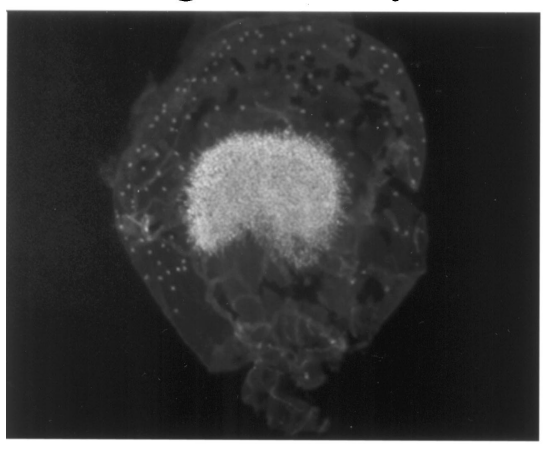

B

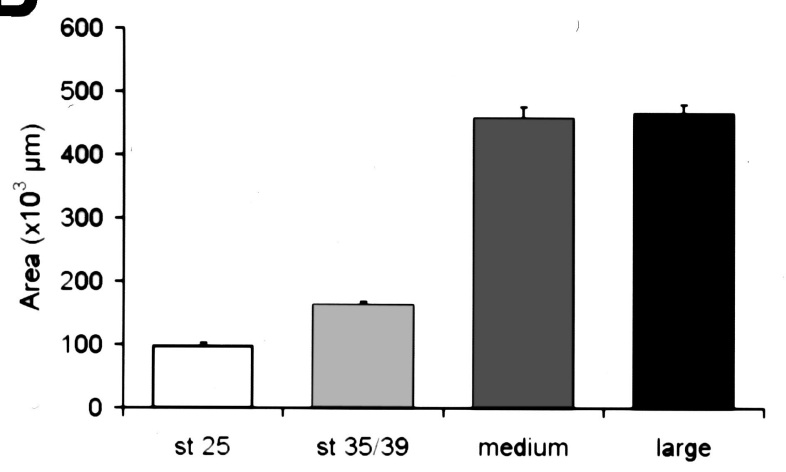

FIG . 6. Extramacular cells are found in the bullfrog saccule at early stages of development. A. HCS-1-labeled hair cells in saccules at three stages of bullfrog development. Extramacular hair cells are present in specimens at all of these stages. $\mathbf{B}$. Histogram of the mean area of the saccular macula in tadpoles at stage $29(n=2)$ and stage $39(n=9)$ and in adult bullfrogs at $12 \mathrm{~cm}(n=6)$ and $15 \mathrm{~cm}$

cells (Gale and Corwin, unpublished observations). Cell divisions were seen in the extramacular epithelium but in no caseswere double-labeled cells observed (data not shown).

\section{DISCUSSION}

U sing a monoclonal antibody that binds to an antigen in hair cell bodies (Finley et al. 1997), we have discovered hair cells surviving in isolation at distances up to $1 \mathrm{~mm}$ from the sensory maculae. Prior to the present report, the extramacular region of the bullfrog saccule has been considered to be nonsensory. Because of their location, we have suggested the term extramacular hair cells. Extramacular hair cells have immature hair bundles and rotund cell bodies. Their morphology appears to be independent of their distance from the edge of the macula. We found that the number of extramacular hair cells does not increase with the age or size of bullfrogs, at least over the lifespan stages that we examined. From the tadpole stage to adult

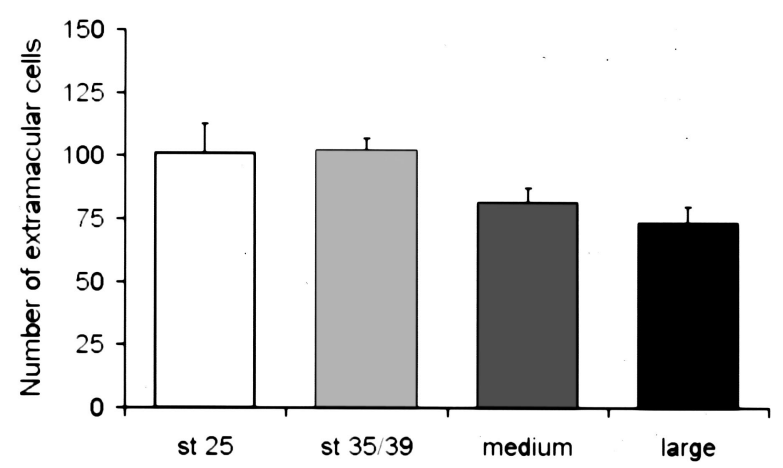

$(n=8)$. O ver this developmental period the area of the sensory macula containing hair cells increased nearly fivefold. C. Counts in the same saccules reveal a small but significant decrease in the number of extramacular hair cells as frogs develop and grow. M eans \pm s.d. are shown. Scale bar $=500 \mu \mathrm{m}$.

stages there appears to be a slight decrease in the number of extramacular hair cells present in the saccule. O ver the same period of animal growth the saccular macula actually increases in area by nearly fivefold (Fig. 6a) as has been described (Lewis and Li 1973; Corwin 1985). Hair cells outside the macula proper were briefly reported by Lewis and Li ( 1973) based on SEM, but they found that the outlying hair cells occur predominantly in the epithelium over the saccular branch of the VIIIth nerve. In contrast, we have found cells that are widely distributed around the macula, but we almost never found extramacular hair cells in the epithelium over the VIIIth nerve.

The morphological characteristics of the hair bundles on the extramacular hair cells-long kinocilia and short stereocilia-suggest that these cells are immature (Lewis and Li 1973, 1975; Corwin 1985). H owever, the immature form of the hair bundles atop the extramacular hair cells may be representative of a cessation of the normal maturation of the hair cell. One possible explanation for such an interruption in a maturation program could be the failure of these 
cells to attach to the otolithic membrane (Kelley et al. 1992). Another possible explanation for an interruption in cellular maturation might depend on the isolation from other hair cells and isolation from the supporting cells within the macula. It is likely that the sensory epithelium of the macula proper contains local signals that may be required for the continued development and maturation of the hair cells. Extramacular hair cells would not receive such signals because of their distance from the macula. Whether and to what degree the epithelial cells that surround the extramacular hair cells are similar to the supporting cells within the macula remains to be determined. Despite this, the presence of extramacular hair cells at great distances from the macular proper clearly shows that hair cellscan survive in the absence of other hair cells.

Immunohistochemical evidence at the light microscopic level shows close associations between extramacular cells and nerve fibers that project out from the macula. The nerve fibers appear to course toward isolated hair cells across large expanses of extramacular epithelium. The nerve fibers may have been attracted to the hair cells, or the hair cell-nerve fiber connections could have been made early in development and maintained during growth of the saccule. We interpret these morphological obser vations as consistent with a high probability that the extramacular hair cells are functionally innervated. We have not attempted to determine the nature of the innervation or confirm connections using ultrastructural analysis or electrophysiological recordings. The present results suggest that innervation alone is not sufficient to stimulate the development of the type of bundle that is completely mature.

Whether these extramacular cells play a role in vestibular or seismic sensory functions remains to be determined. However, the finding that the majority, and potentially all, of the extramacular hair cells come into intimate contact with nerve fibers suggests that these cells do have a physiological function. The hair bundles of the cells in the macula are embedded in an otolithic membrane (Lewis et al. 1985) that sits beneath the otoconial mass. The otolithic membrane covers only the macular region and does not cover the regions where most of the extramacular hair cells reside. H owever, the otoconial mass itself fills most of the saccule, so the long kinocilia of the extramacular hair cells could be influenced directly by the motion of the otoconial mass. As a result of this, the mechanical coupling of hair bundles to the otoconial mass would differ between extramacular and macular hair cells, so the two types of hair cells may report different sorts of stimuli to the CNS.

We have shown that extramacular hair cells can be quickly identified in live preparations by labeling with the styryl dye FM 1-43, which also labels hair cells in the lateral line organs (Nishikawa and Sasaki 1996; Seiler and Nicholson 1999). This should allow the cells to be easily located for physiological studies.

An intriguing question is whether these cells are (i) produced where they are found, i.e., from divisions of cells in the epithelium that extends far from the macula proper, or (ii) produced in the growth zone at the edge of the macula and then pushed out into the surrounding epithelium by the continued production and growth of cells surrounding the macula. A third alternative is that the extramacular hair cells are produced near the macula and then actively migrate away from its edge. The rotund morphology of these hair cells does not suggest that they are actively migrating, so we do not favor that hypothesis. In an attempt to test hypothesis (i), we cultured tadpole saccules for up to 14 days in the presence of the BrdU, a tracer that is incorporated into DNA during S-phase. Results from 30 tadpole saccules failed to reveal any extramacular cells that were double-labeled by the anti-calretinin and anti-BrdU antibodies. Thisnegative result does not allow support or rejection of the hypothesis that extramacular hair cells can be produced from cell divisions that occur out in the extramacular epithelium. H owever, it does suggest that these cells are not produced at a high rate.

O ur results provide some support for hypothesis (ii), that the extramacular hair cells originate at an early stage of development of the saccule and are then pushed out to extreme distances by the continued growth of the saccule. First, extramacular hair cells are found in the saccules from stage 29 tadpoles (Fig. $6 \mathrm{~A})$. At this stage they are already distributed over much of the nonsensory epithelium that surrounds the macula proper. Second, almost all extramacular hair cells in both tadpoles and adults appear to be innervated (Fig. 4). This high proportion of neural connectivity occurs despite there being relatively few nerve fibers in the extramacular epithelium. Of course, that may depend on survival of only those nerve fibers that make synapses with hair cells in that region. Third, the number of extramacular hair cells decreases as frogs and their saccules grow in size. O ver the same stages of growth the number of epithelial cells in the extramacular region will have increased considerably. If some small percentage of the epithelial cells in the extramacular region have the potential to produce extramacular hair cells, then according to hypothesis (i) we might predict that the numbers of extramacular hair cells would increase as the total number of cells in that region increases with growth of the saccule.

It may be that the extramacular hair cells fail to attach into the otolithic membrane at a ver y early stage in development (certainly prior to tadpole stage 29). 
At that stage the neural connections may be set up and, thus, the connections would be maintained throughout the life of the extramacular hair cell. If this hypothesis is correct, the extramacular hair cells probably do not actively migrate out into the expanse of the extramacular epithelium but instead are pushed outward passively by the interstitial growth of cells that occurs between the edge of the macula and the individual extramacular hair cells.

The absence of extramacular hair cells from the region above the saccular ramus of the VIIIth nerve was a consistent finding in the saccules that we examined. The underlying cause for this remains to be determined. Extramacular cells were seen on the posteriomedial side of the nonsensory epithelium where the lagena is found. It is possible that some of the extramacular cells arise from the sensory patch that will form the lagena.

The occurrence of extramacular hair cells is not restricted to bullfrogs. Extramacular hair cells are also found in lesser numbers in the neotropical toad (Bufo marinus) saccule (Gale and Corwin, unpublished observations) and in the saccule of the newt ( $N$ otophalmus viridiscens; A. Forge, personal communication). It is not clear whether the extramacular hair cells are an amphibian specialization or a general phenomenon where there is sufficient extramacular epithelium to support the cells. Further work is required to determine whether these cells are found in other vertebrate species and to determine their physiological role in each system.

In summary, we have described numerous solitary hair cells that occur throughout the extramacular epithelium of the bullfrog sacculus that has been considered nonsensory. The extramacular hair cells appear to be innervated and may well live a solitary existence for the life span of the bullfrog. The extramacular hair cells may arise at an early stage of development and then may be moved outward, pushed by the growth of epithelial cells in the growth zone that surrounds the macula proper. However, we cannot reject the tantalizing hypothesis that cells in the columnar nonsensory epithelium that surrounds the macula of the bullfrog saccule may be able to act as the progenitors of hair cells. Whether that isthe case and whether these cells serve a unique physiological function remain to be determined.

\section{ACKN O W LED G MENTS}

Thanks go to James Finley for initial help in this study and Jan Redick and Bonnie Sheppard of the Central Electron Microscopy facility at the University of Virginia. We thank David Lenzi for critical comments on the manuscript. The work was supported by a Wellcome Trust International Prize
Travelling Fellowship (JEG), by a H oward Hughes Medical Institute Predoctoral Fellowship (JRM), and by NIDCD grant R01-DC00200 (JTC).

\section{REFEREN CES}

BAIRD RA. Comparative transduction mechanisms of hair-cells in the bullfrog utriculus. 1. Responses to intracellular current. J. Neurophysiol. 71:666-684, 1994a.

BAIRD RA. Comparative transduction mechanisms of hair-cells in the bullfrog utriculus. 2. Sensitivity and response dynamics to hair bundle displacement. J. Neurophysiol. 71:685-705, 1994b.

BAIRD RA, TORRES MA, SChufF NR. Hair cell regeneration in the bullfrog vestibular otolith following aminoglycoside toxicity. $\mathrm{H}$ ear. Res. 65:164-174, 1993.

BAIRD RA, LEWISER. Correspondences between afferent innervation patternsand response dynamicsin the bullfrog utricle and lagena. Brain Res. 369:48-64, 1986.

BETZ WJ, MAO F, BEWICK GS. Activity dependent fluorescent staining and destaining of living vertebrate motor nerve terminals. J. Neurosci. 12:363-375, 1992.

COREY DP, HUDSPETH AJ. Ionic basis of the receptor potential in a vertebrate hair cell. Nature 281:675-677, 1979.

CORWIN JT. Postembryonic production and aging of inner ear hair cells in sharks. J. Comp. Neurol. 201:541-553, 1981.

CoRWIN JT. Perpetual production of hair cells and maturational changes in hair cell ultrastructure accompany postembryonic growth in an amphibian ear. Proc. Natl. Acad. Sci. USA. 82:39113915, 1985.

FINLEY JE, XIA B, CORWIN JT. Monoclonal antibodies raised as markers for supporting cells and hair cells. Assoc. Res. Otolaryngol. Abstr. 20:134, 1997

GALE JE, Corwin JT. H air cell repair after ototoxic damage: a timelapse and culture study in the bullfrog sacculus. Soc. Neurosci. Abstr. 23:1822, 1997.

GALE JE, CoRwin JT. Numerous solitary hair cells are distributed throughout the extra-macular epithelium in the bullfrog's saccule. Assoc. Res. Otolaryngol. Abstr. 21:120, 1998.

GOSNER KL. A simplified table for staging anuran embryos and larvae with notes on identification. Hepetologica 16:183-190, 1960.

HILLMAN D, LEWIS ER. Morphological basisfor a mechanical linkage in otolithic receptor transduction in the frog. Science 174:416419, 1971

H UDSPETH AJ. H ow the ears works work. Nature 341:397-404, 1989.

HUDSPETH AJ, COREY DP. Sensitivity, polarity, and conductance change in the response of vertebrate hair cells to controlled mechanical stimuli. Proc. Natl. Acad. Sci. USA. 74:2407-2411, 1977.

Kelley MW, OChial CK, CoRWIN JT. Maturation of kinoclia in amphibian hair cells: Growth and shortening related to kinociliary bulb formation. Hear. Res. 59:108-115, 1992.

LEWIS ER, LI CW. Evidence concerning the morphogenesis of saccuIar receptorsin the bullfrog Rana catesbeiana. J. Morphol. 139:351362, 1973.

LEWIS ER, LI CW. Hair cell types and distributions in the otolithic and auditory organs of the bullfrog. Brain Res. 83:35-50, 1975.

LEWIS ER, BAIRD RA, LEVERENZ EL, KoyAma H. Inner ear: dye injection reveals peripheral origins of specific sensitivities. Science 215:1641-1643, 1982.

LEWIS ER, LEVERENZ EL, BIALEK WS. The Vertebrate Inner Ear CRC Press, Boca Raton, FL, 1985, 248.

MALICK LE, WILSON RB. Modified thiocarbohydrazide procedure for scanning electron microscopy: routine use for normal, patho- 
logical, and experimental tissues. Stain Technol. 50:265-269, 1975.

NISHIKAWA S, SASAKI F. Internalization of styryl dye FM1-43 in the hair cells of lateral line organs in Xenopus larvae. J. Histochem. Cytochem. 44:733-741, 1996.

SeILER C, NiChOLSON T. Defective calmodulin-dependent rapid apical endocytosis in zebrafish sensory hair cell mutants. J. Neurobiol. 41:424-433, 1999.
Steyger PS, Burton M, HaWkins JR, Schuff NR, Baird RA. Calbindin and parval bumin are early markers of non-mitotically regenerated hair cells in the bullfrog vestibular otolith organs. Int. J. Develop. Neurosci. 15:417-432, 1997.

Wersall J, BAgGer-Sjoback D. Morphology of the vestibular sense organ. KornhUBer HH. Vestibular system: basic mechanisms. $\mathrm{H}$ andbook of sensory physiology Springer, Berlin, 1974, 123-170, Vol VI 1. 